\title{
A COORDINATION LEVEL IN SUPPLY CHAIN SIMULATOR
}

\author{
Marcius Fabius Henriques Carvalho ${ }^{1}$ \\ Carlos MACHADO ${ }^{2}$ \\ ${ }^{I}$ CENPRAVUNICAMP - marcius.carvalho@cenpra.gov.br \\ ${ }^{2}$ UNICAMP - cmachado@fem.unicamp.br
}

\begin{abstract}
This paper suggests a two level simulation tool for supporting the planning decision of a supply chain. The first level coordinates the business process among enterprises through decision rules while the second level analyzes the behavior of each enterprise subjected to the targets established by the coordination level.
\end{abstract}

\section{INTRODUCTION}

A Supply Chain can be defined as a network of autonomous or semi-autonomous business entities (department, plant, enterprise) collectively responsible for the procurement, manufacturing and distribution activities associated with one or more families of related products. Supply Chain Management is a process-oriented, integrated approach, which crosses the enterprise boundaries, to manage the above system in procuring and producing activities, delivering products and services to customers. It has a broad scope including sub-suppliers, suppliers, internal operations, trade customers, retail customers, and end-users. To execute an effective management, looking for the best design or operation point in the supply chain, is necessary to model the information, production and control flow inside each participant and among partners. But the participants might not be enthusiastic to share their strong and weak points or operation secrets with all other partner enterprises. Moreover financial data, cost data, client data and others would be kept inside the enterprise but, to get better results for the integrated system, targets data of these items would be shared. Then the group of enterprises should share information to reach the corporation objectives through a model of the entire system, but due to strategic reasons, this policy would be restrict to some information level.

The design, planning and operation of this integrated system, considering the conflicting objectives, are difficult tasks needing to be supported by computational tools. Analytical models are too complex to solve this class of problem and simulation tools have gained considerable attention (Lee and Billington, 1993) as a vehicle for an organizational decision-making process. The system simulation has evolved fast since the 80 s and many commercial tools have emerged (Davis, W. J., 1998). Once Supply Chain models demand a specific requirement, commercial tool 
is not suitable to build a supply chain simulation models efficiently (Vernadat, 1999).

This work proposes a two level distributed modeling and simulation technique as supporting technology that allows a group of enterprises to construct a simulation model and to conduct a supply chain business process through a precise representation of the enterprises as well as business process among them. In the lower level, the enterprise level, each enterprise models and runs its own simulation model at its own site. The detailed model (application codes and data) information is encapsulated within the corporation and the external integration of this corporation occurs thought essential information exchange following a predefined business process structure. The second level coordinates the integration of the business process models according to the Supply Chain structure and management rules.

\section{DECISION LEVELS FOR A SUPPLY CHAIN}

To understand how the system works is important for the development of a precise simulation model. This section describes the material and information flow in an assembly sub-chain considering mainly two points: 1) in a large production system, a dozen changes occur in a short period of time. However, many of them turn out to be self-canceling or can be accommodated within a system slack. Then, at the enterprise business process level, the significant changes can be taken into account through the consideration of a fixed time interval in which all changes are accumulated and the final effect of them considered for the decision making process among enterprises. The time interval length can have different length for each pair of partner enterprises. 2) These changes are important at the enterprise level since they describe the dynamic behavior of the production system and the ability of an enterprise to meet the supply chain objectives. At this level is necessary a precise description of the events only possible through a discrete event representation.

Two decision levels are identified of the above consideration: The level for coordination of the business process among enterprises and the level to represent the dynamics of the enterprises. The coordination decision level considers the business process among enterprises. Events representing these decisions as new information or new material flow among enterprises (sending product, order, order confirmation, etc.) occur at a discrete time interval (daily, weekly) driving by business process rules and agreements previously established.

The discrete time business process can be described as: at the end of each period, there is a final event, representing the accumulated changes that every enterprise sends to the coordination level. In general, these events are goods been shipped, planned capacity for the next period, orders been requested and unpredictable events. Upstream partners send goods while downstream enterprises send requests according to their internal rules (new order, product shipped, warning of machine breakdown, etc.). After receiving the events of every enterprise, the coordination level use decisions rules to establish production target to be pursued for every supply chain member. 
The information and material flow between enterprises occur at discrete time period and represent the supply chain dynamics, as shown in the Figure 1. The production of supplier 1 and supplier 2 , during the interval $\mathrm{T}=1 \mathbf{\Delta}$, are shipped to be assembled at time $\mathrm{T}=2 \Delta$ (taking the delay period equal to 1 ) and to be delivered to the warehouse at time $T=3 \mathbf{\Delta}$. Also during the time $T=1 \mathbf{\Delta}$, the assembly enterprise plans its future activities, based on the warehouse requests sent at the end of time $\mathrm{T}=0 \mathbf{\Delta}$, and places orders to the suppliers $\mathrm{S} 1$ and $\mathrm{S} 2$ to be produced during the time $\mathrm{T}=2 \mathbf{\Delta}$.
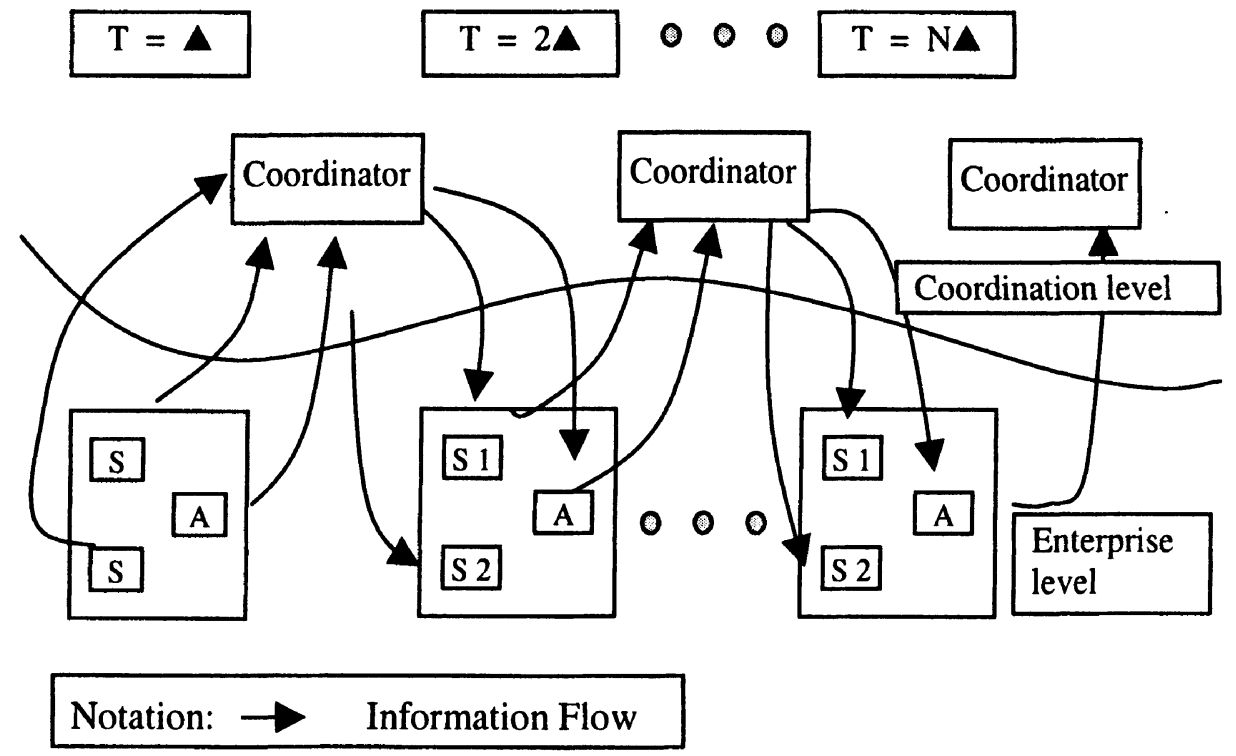

Figure 1. Supply Chain and Enterprise Information Exchange

\section{THE TWO LEVEL SIMULATOR}

A two-level simulation hierarchy is suggested for supporting the designing and planning activities within a supply chain, Figure 2 . In this hierarchy every enterprise processes its discrete event simulation in the time interval $(t \boldsymbol{\Delta},(t+1) \boldsymbol{\Delta})$ and, at the end of this interval, sends its final state (through vector of events) to the supply chain coordination level, as shown in the Figure 1.

At each time interval, the coordination model receives the vectors of the enterprise's state and starts its simulation, while the enterprise simulator clocks are stopped. The decisions at the coordination level are based on the enterprises states and rules agreed among enterprises and are taken in a sequence of discrete time intervals $(0, \boldsymbol{\Delta}, 2 \boldsymbol{\Delta}, \ldots)$. This level generates new targets to every enterprise. At the enterprise level the discrete event simulation occurs in the time interval $(t \boldsymbol{\Delta},(t+1)$ $\boldsymbol{\Delta})$. The results of these simulations, represented by a vector of enterprise state, are sent to the coordination level that generates production/orders targets to be pursued by the enterprises in the next time interval $((t+1) \boldsymbol{\Delta},(t+2) \mathbf{\Delta})$. A three-stage supply chain, shown in the Figure 3, is taken as reference to analyze the influence of two different information management policies in the bullwhip effect. 


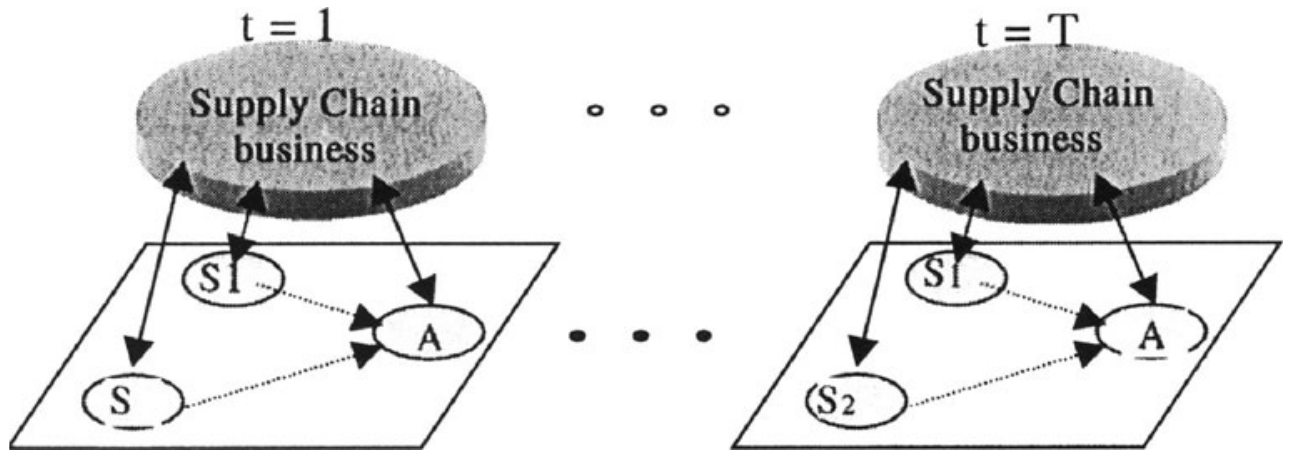

Figure 2. Two Level Simulator

These policies are: Decentralized Information Management System (DIMS) and Centralized Information Management System (CIMS). In the DIMS, the demand information flows upstream of the Supply Chain enterprise by enterprise. In the CIMS the demand is communicated immediately to every supply chain members as shown by dashed line in the Figure 3.

In the traditional management policy, scenario one, each supply chain participant performs its role and then passes product and/or information to the next enterprise in the line. That implies linear flow of information and processes up and down the supply chain and limited information about the end customer behavior for the upstream supply chain components. This approach causes demand distortion, known as bullwhip effect (Lee, Padmanabhan and Wahng, 1997), as it is interpreted, processed and propagated upstream in the chain. This distortion produces several operational inefficiencies as: excessive inventory, poor production forecast and customer service, misguided capacity plans, ineffective transportation, etc.

The integration and coordination of the information is the way to overcome these distortions in the supply chain. Integration means to consider both, business process among enterprises defined by predefined rules and at the same time the internal business process of the enterprises. The evaluation of the implementation of this scenario is possible through the simulation of a Centralized Information Management System where each enterprise is considered as an autonomous agent and its messages are equivalent to events that will start the actions of others agents in the next period of time coordinated by the supply chain management level.

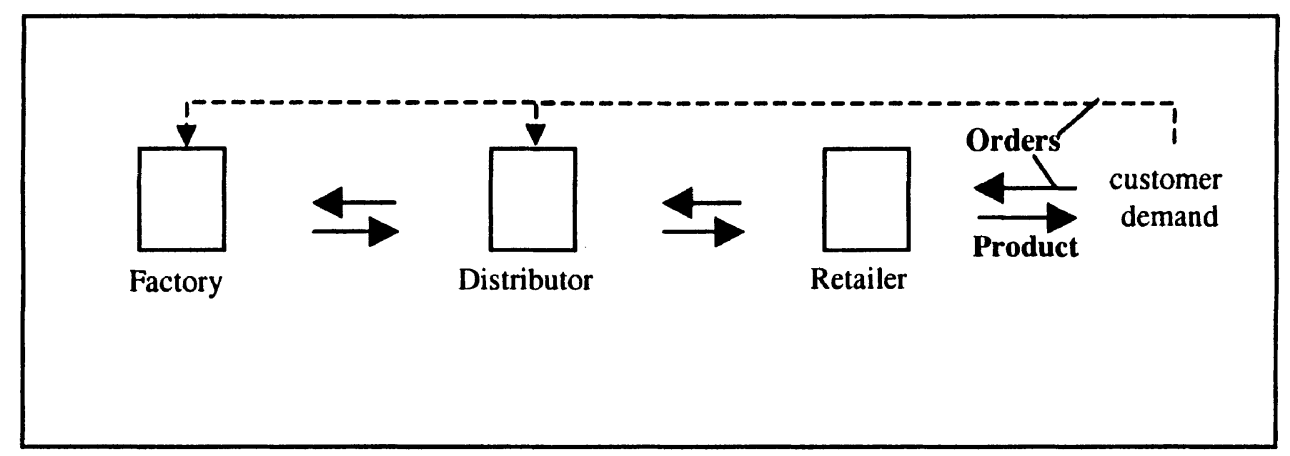

Figure 3 - The Supply Chain Management Models 
The simulation schema above suggested is defined as distributed simulation, with spatially decomposition of the simulation model through enterprises (corporation, departments). The objective of distribution is to maintain the encapsulation of each partner enterprise model preserving their secrets, but allowing the coordination of enterprises operations by the coordination level. In this schema, it is not necessary to encode an explicit synchronization strategy in a distributed simulation program since the simulation of the coordination level evolves in a discrete time interval. This strategy considerably simplifies the implementation of the synchronization mechanism as described in the next section.

\section{THE COORDINATION PROCESS}

The simulation environment for the coordination level represents sales forecasting, as well as inventory management, dispatching and procurement polices modeled by rules and equations. The supply chain manager can customize its model by choosing from a specific template the rule or equation that describes the enterprises agreement or enterprise behavior. For instance, in the sales forecasting template provides the following techniques: moving average, exponential smoothing, linear regression and time series.

Both management polices of Figure 3 are modeled by choosing correctly rules and parameters to describe the business process among enterprises. The templates for the factory/assembler and distributor/retailer, shown in the Figures 4 and 5, model the DIMS scenario. The Factory demand forecast is defined as a ten period moving average based on the distribution's orders, Figure 4 . The inventory policy is chosen as reorder point with demand uncertainty. Some predefined order rules are available to be chosen. The expression to calculate the reorder point has attributes defined by the manager. The fields "Buyers" and "Suppliers" specify the buyer and the supplies of this Factory. Other attributes to model the Factory are listed in the field "Attributes:" The variable AVG, calculated by the AVERAGE function is defined as: mean of the last ten orders received from the distributor.

The coordinator template, Figure 5, coordinates the interrelation among enterprises in the DIMS scenario. Also, this template describes the interaction of external elements with the supply chain (clients and the supplier of the factory). In this example, there are two external elements: "CLIENTS" and "SUPPLIER". The CLIENT has its demand generated from a random variable that follows normal distribution function with mean equals to 40 and variance equals to 4 . The SUPPLIER supplies material to the Factory with $97 \%$ of service level. The coordinator template allows the manager to specify some indicator functions for evaluating the performance of each supply chain member. In this example, the inventory turnover is defined as a performance indicator.

In the CIMS scenario, the sales forecast, the inventory and the production rules as well as demand sharing are defined at the coordinator template. In the Figure 6 representing the Factory template, is specified who sends and what kind of information is sent and the policies that drive the process. The coordinator template, Figure 7, defines the contract between the Factory and the Distributor and the configuration of the information flow. This Figure shows that the Distributor and the Factory share demand information. 


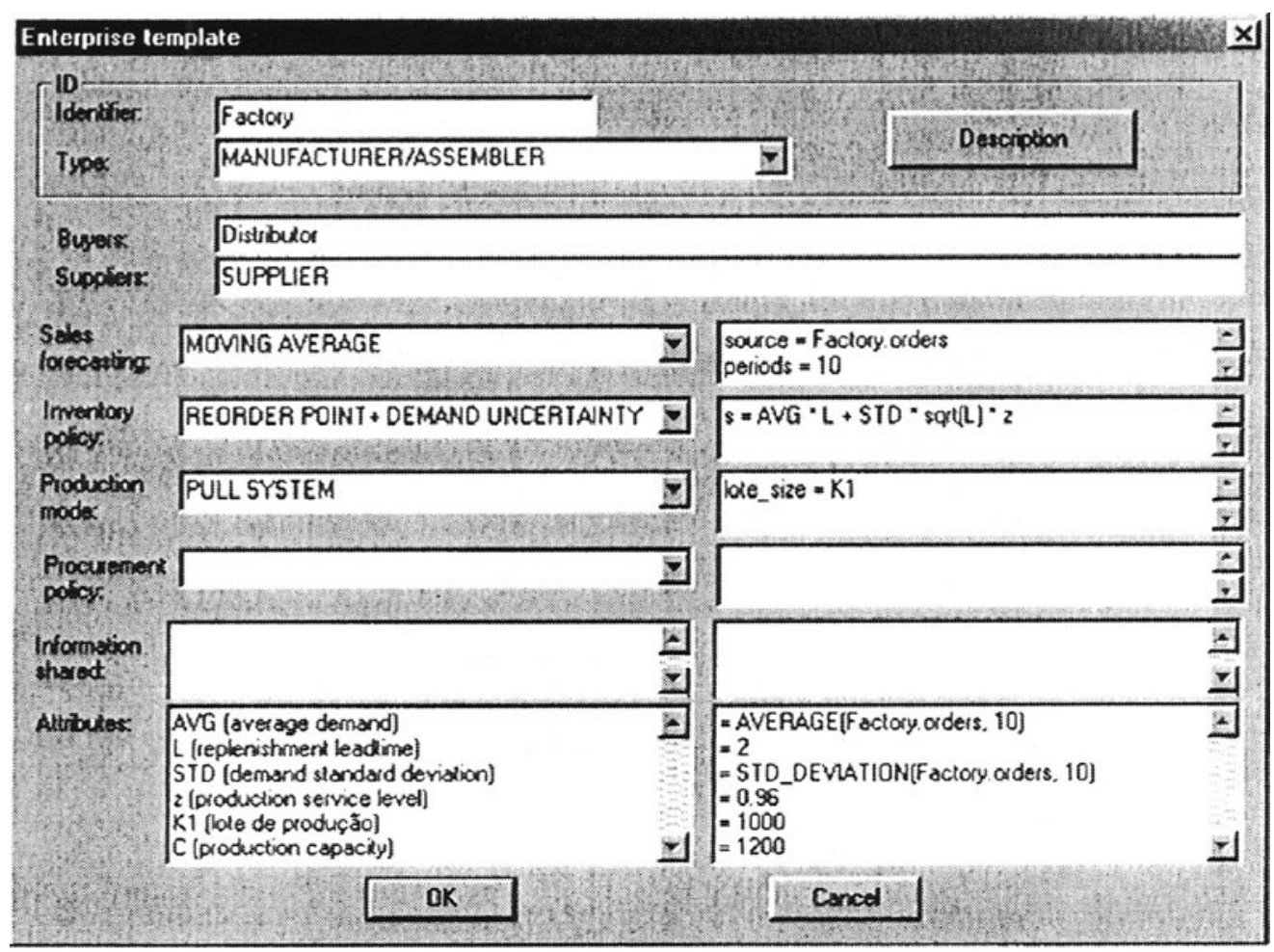

Figure 4 - Factory Template

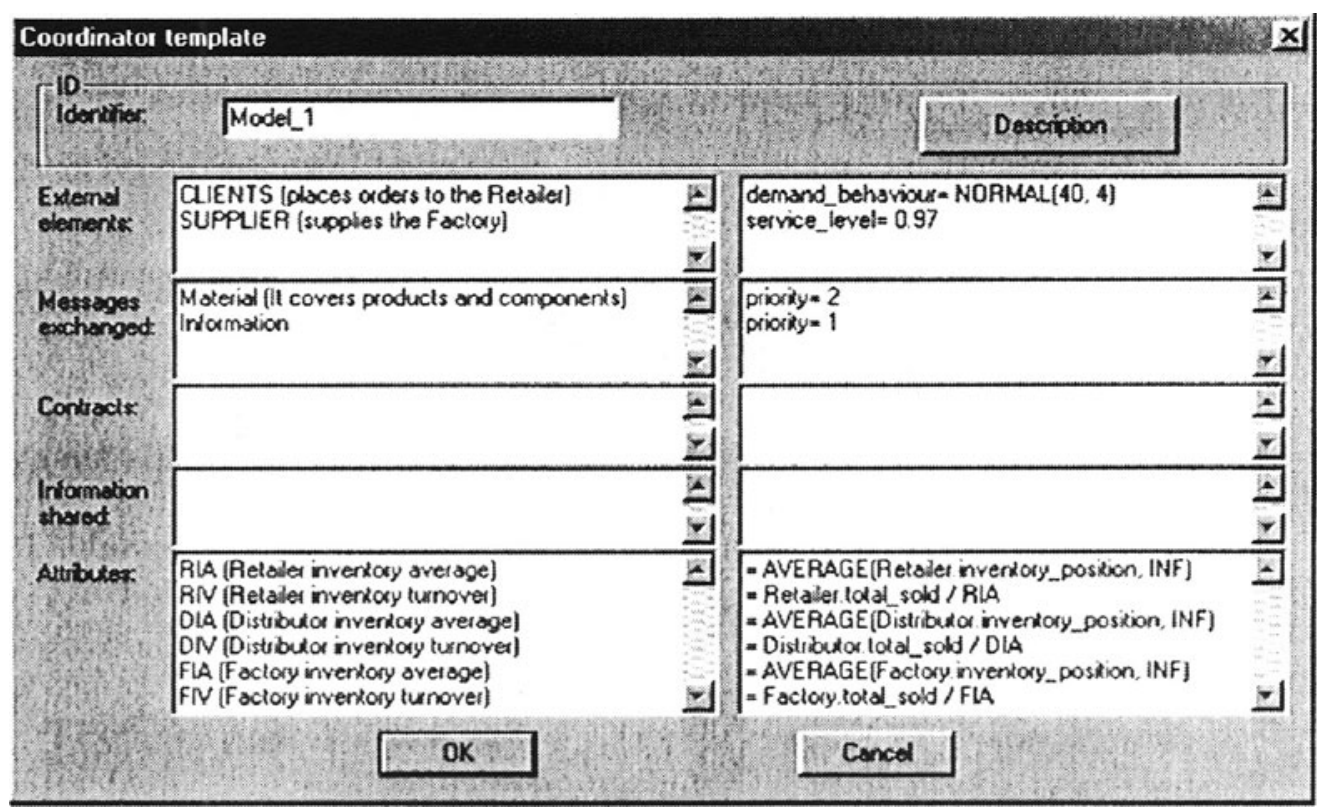

Figure 5 - Coordinator Template 


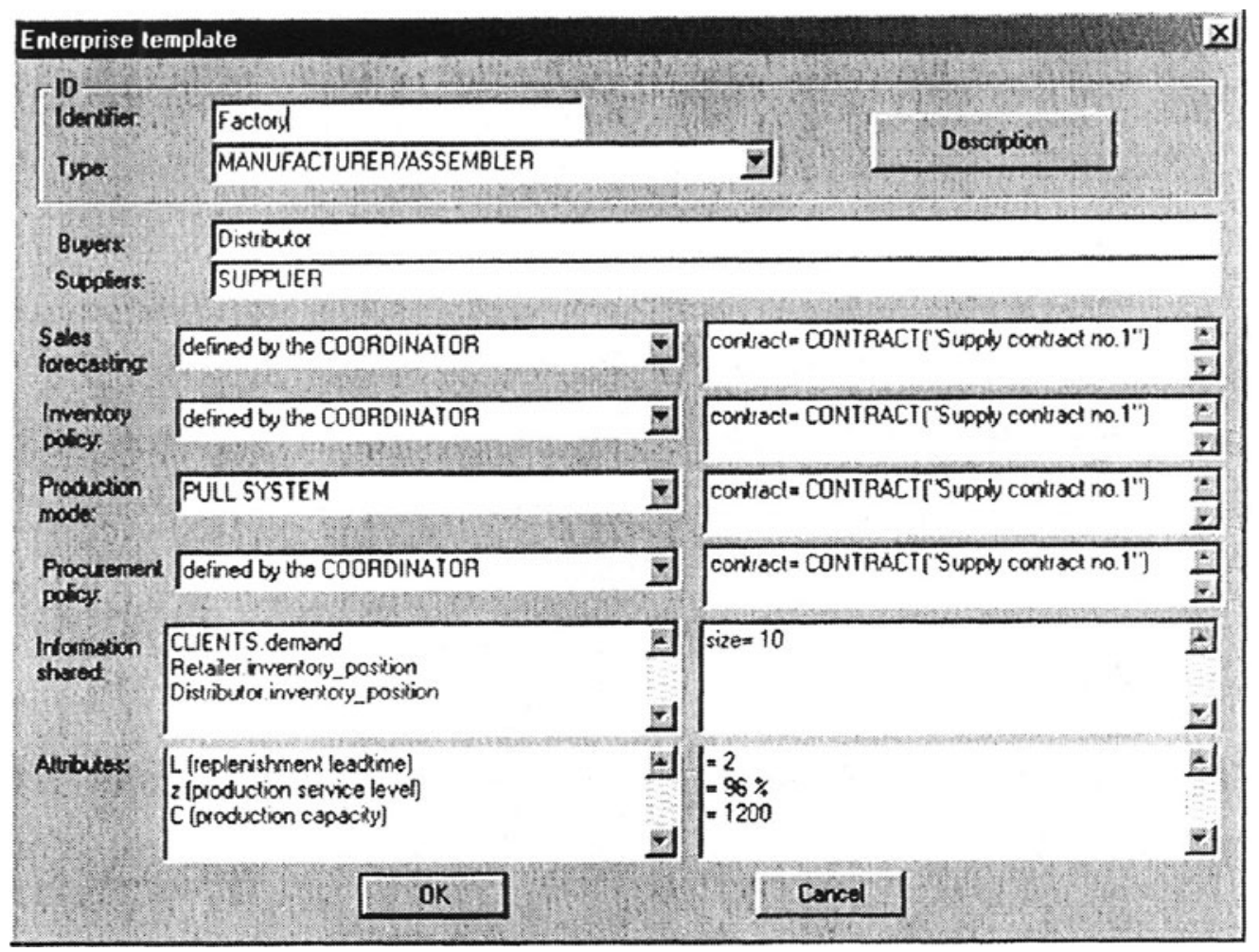

Figure 6-Enterprise Template

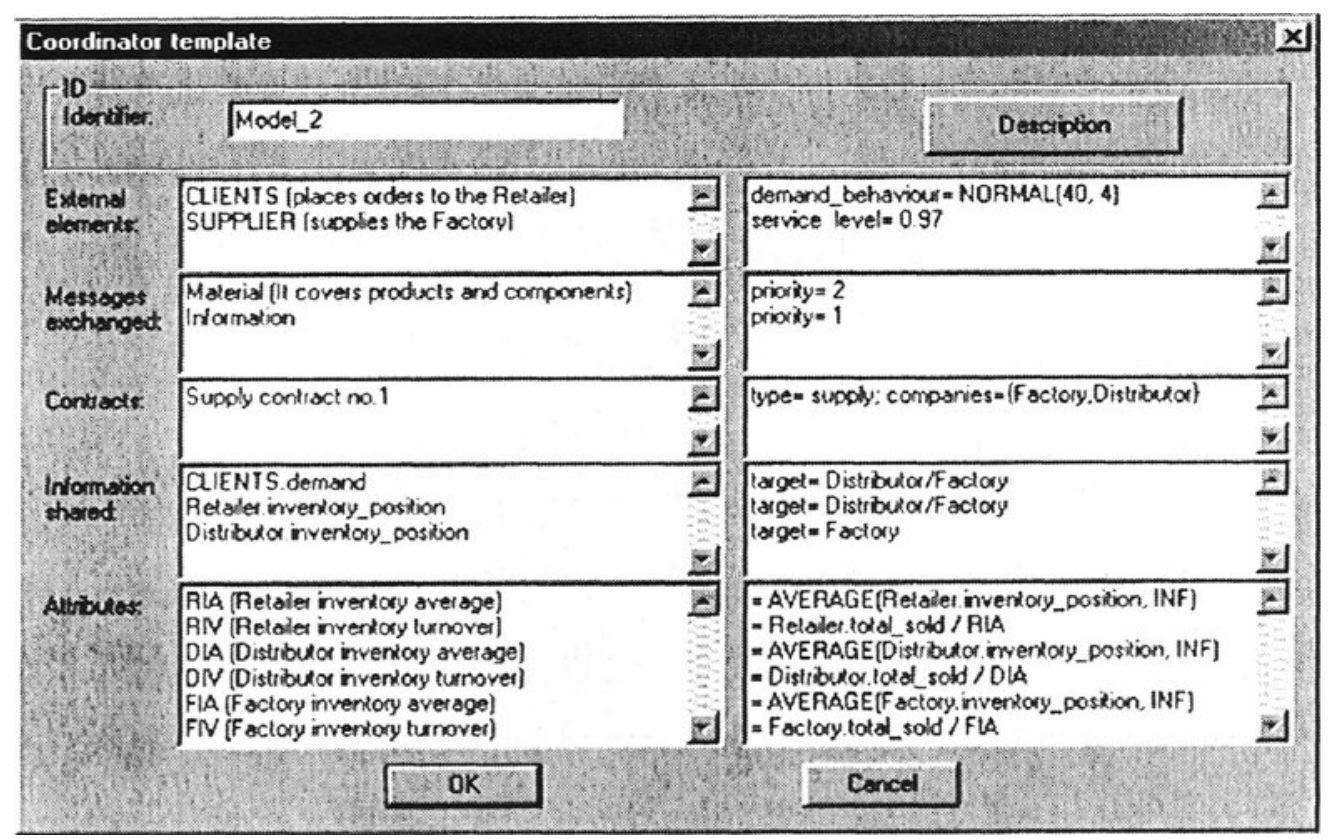

Figure 7 - Coordinator template

The figure 8 shows the Factory, the Distributor and the Retailer inventory dynamics during 100 periods of time for each one of the two above management scenarios. The largest inventory level, in the scenario CIMS, occurs at the retail and 
is half of in the DIMS scenario. Also in the CIMS scenario the inventory has better behavior than in the DIMS approach.
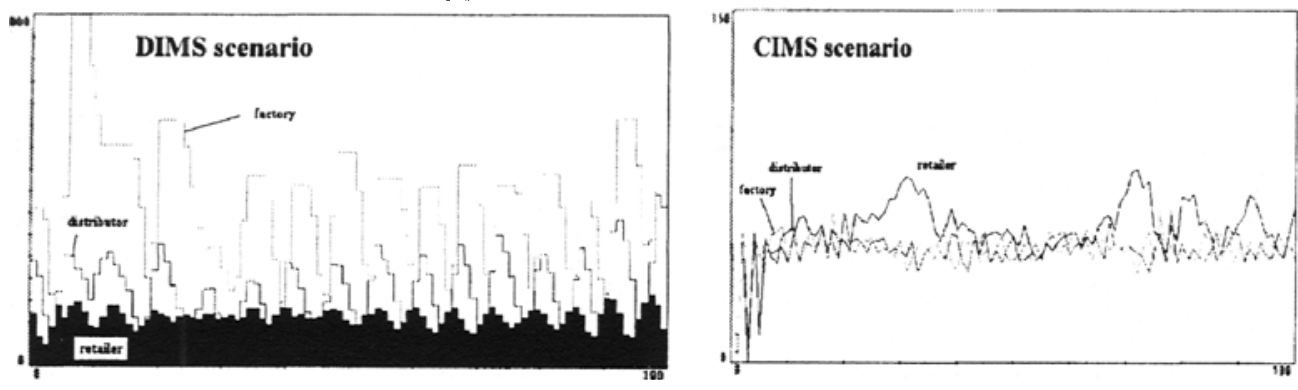

Figure 8 - Inventory Dynamics

\section{CONCLUSIONS}

New Supply Chain strategies are necessary to provide the market with high-mix, low volume, fast response at low costs products. These challenges require customeroriented Supply Chain operations through re-engineering the business processes among partner enterprises. System simulation is an important decision support tool that can contribute to re-think these processes. A specialized simulation tool is necessary to consider a distributed modeling and simulation environment oriented to business process rules.

\section{ACKNOWLEDGMENTS}

The research reported in this paper was supported by FAPESP (Fundação de Amparo à Pesquisa do Estado de São Paulo) through a scholarship to Carlos Machado and CNPq through a research project.

\section{REFERENCES}

1. Al-Ahmari, A.M. and Ridgway, K. "An integrated modeling method to support manufacturing systems analysis and design", Computer in Industry. Vol. 38 (1999).

2. Bruno, G., Agarwal, R. "Modeling the Enterprise Engineering Environment", IEEE Transactions on Engineering Management. Vol. 44, No. 1 (1997).

3. Davis, Wayne J. "Looking into the Future of Simulation", IEEE Solutions, May (1998).

4. Kellert, P., Tchernev, N., Force, C. "Object Oriented Methodology for FMS modelling and simulation", International Journal of CIM. Vol. 10, No. 6 (1997).

5. Lee, H.L., Billington, C. "Material Management in Decentralized Supply Chains", Operations Research. Vol. 41, No. 5 (1993).

6. Lee, H.L., Padmanabhan, V. and Whang, S. "Information distortion in a supply chain: the bullwhip effect", Management Science. Vol. 43, 546-558 (1997).

7. Simchi-Levi, D., Kaminsky, P. and Simchi-Levi, E. (2000) Designing and Managing the Supply Chain: Concepts, Strategies, and Cases. McGraw-Hill.

8. Vernadat, F. "Requirements for Simulation Tools in Enterprise Engineering". CAR\&FOF'99, August, MT5/19-23 (1999).

9. Whitman, L., Huff, B. and Presley, A. (1997). "Structured Models and Dynamic Systems Analysis: The Integration of the IDEF0/IDEF3 Modeling Methods and Discrete Event Simulation". Winter Simulation Conference (1997). 